\title{
The potential health benefits of legumes as a good source of dietary fibre
}

\author{
Trinidad P. Trinidad*, Aida C. Mallillin, Anacleta S. Loyola, Rosario S. Sagum and Rosario R. Encabo \\ Department of Science and Technology, Food and Nutrition Research Institute, Gen Santos Avenue, Bicutan, Taguig City, \\ Metro Manila 1631, Philippines
}

(Received 22 May 2009 - Revised 24 August 2009 - Accepted 26 August 2009 - First published online 14 October 2009)

Dietary fibre has been shown to have important health implications in the prevention of risks of chronic diseases. The objective of the present study was to determine the potential health benefits of legumes as a good source of dietary fibre. Six to ten local legumes were studied as follows: cowpeas, mung beans, pole sitao, chickpeas, green peas, groundnuts, pigeon peas, kidney beans, lima beans and soyabeans. The following studies were conducted: (a) mineral availability, in vitro; (b) glycaemic index (GI) in non-diabetic and diabetic human subjects; (c) the cholesterollowering effect in human subjects with moderately raised serum cholesterol levels. The highest Fe availability among legumes was for lima beans (9.5 (SEM 0.1)) while for $\mathrm{Zn}$ and Ca, the highest availability was for kidney beans (49.3 (SEM 4.5)) and pigeon peas (75.1 (SEM 7.1)), respectively. Groundnuts have the lowest Fe (1.3 (SEM 1.1)), Zn (7.9 (SEM 1.3)) and Ca (14.6 (SEM 2.8)) availability. Legumes are low-GI foods $(<55)$, ranging from 6 (chickpeas) to 13 (mung beans). Kidney beans showed significant reductions for both total (6\%) and LDL-cholesterol (9\%), and groundnuts for total cholesterol $(7 \% ; P<0.05)$. We conclude that mineral availability from legumes differs and may be attributed to their mineral content, mineral-mineral interaction and from their phytic and tannic acid content; legumes are considered low-GI foods and have shown potential hypocholesterolaemic effects. The above studies can be a scientific basis for considering legumes as functional foods.

Legumes: Functional foods: Dietary fibre

Dietary fibre has been shown to have important health implications in the prevention of risks of chronic diseases such as cancer, CVD and diabetes mellitus. It comes from the family of carbohydrates, an NSP, not digested in the small intestine but may be fermented in the colon into SCFA such as acetate, propionate and butyrate. SCFA contribute $6.3-8.4 \mathrm{~kJ} / \mathrm{g}(1.5-2.0 \mathrm{kcal} / \mathrm{g})$ dietary fibre ${ }^{(1)}$. They enhance water absorption in the colon, and thus prevent constipation. Propionate has been shown to inhibit the activity of the enzyme hydroxy-3-methylglutaryl-CoA reductase, the limiting enzyme for cholesterol synthesis. Dietary fibre has the ability to bind with bile acids and prevents their reabsorption in the liver, and thus inhibit cholesterol synthesis ${ }^{(2)}$. Butyrate enhances cell differentiation, thus preventing tumour formation in the colon ${ }^{(3)}$. Dietary fibre's viscous and fibrous structure can control the release of glucose with time in the blood, thus helping in the proper control and management of diabetes mellitus and obesity ${ }^{(4,5)}$. The glycaemic index (GI), a classification of food based on the blood glucose response relative to a starchy food, for example, white bread, or a standard glucose solution, has been proposed as a therapeutic principle for diabetes mellitus by slowing carbohydrate absorption $^{(4,5)}$. Low-GI foods, for example, high-dietary fibre foods, have been shown to reduce postprandial blood glucose and insulin responses and improve the overall blood glucose and lipid concentrations in normal subjects and patients with diabetes mellitus ${ }^{(6-9)}$. A previous study on dietary fibre and fermentability of legumes showed that legumes are good sources of dietary fibre $(21-47 \mathrm{~g} / 100 \mathrm{~g}$ sample), fermentable in the colon, and produce SCFA such as acetate, propionate and butyrate ${ }^{(10)}$.

The general objective of the present study is to determine the potential health benefits of legumes as good sources of dietary fibre. The specific objectives are as follows: (a) to determine mineral availability in vitro from legumes; (b) to determine the GI of legumes from non-diabetic and diabetic human subjects; (c) to determine the cholesterol-lowering effect of legumes in human subjects with moderately raised serum cholesterol level. The utilisation of legumes as functional foods will not only solve the problem of micronutrient deficiencies and chronic diseases now prevailing in almost all countries but also encourage the industry and farmers to produce value-added or healthy products from legumes.

\section{Materials and methods}

\section{Test foods}

In the present study ten legumes were used as test foods: cowpeas (Vigna unguiculata (L.) Walp.), mung beans (V. radiata (L.) R. Wilczek), pole sitao (V. unguiculata subsp. sesquipedalis (L.) Verde), chickpeas (Cicer arietinum), green peas (Pisum sativum L.), groundnuts (Arachis hypogaea L.), pigeon peas (Cajanus cajan), kidney beans (Phaseolus 
vulgaris L.), lima beans (Phaseolus lunatus) and soyabeans (Glycine soja). Food samples were bought in local markets. Legumes were soaked in water overnight, and boiled to cook the next day. Legumes were freeze-dried before analyses.

\section{Analytical methods}

The proximate analysis, and analysis of dietary fibre and SCFA content of legumes were performed previously ${ }^{(10-11)}$.

Total $\mathrm{Fe}, \mathrm{Zn}$ and $\mathrm{Ca}$ were analysed by the wet digestion method. A $0 \cdot 1 \mathrm{~g}$ sample of freeze-dried test food was weighed and dissolved in $1 \mathrm{ml}$ of $36 \mathrm{~N}$-sulfuric acid (Analytical Reagent; Ajax Chemical, Auburn, NSW, Australia) and $3 \mathrm{ml}$ of $30 \% \mathrm{H}_{2} \mathrm{O}_{2}$ (Analytical Reagent; Ajax Chemical), and made up to $50 \mathrm{ml}$ volume with double deionised water. For $\mathrm{Ca}$, the digested sample was made up to $50 \mathrm{ml}$ volume with 10 mm-lanthanum chloride (Analytical Reagent, Asia Pacific Specialty Chemical Limited, Seven Hills, NSW, Australia). The resulting solution was read in an atomic absorption spectrophotometer (Buck Scientific, East Norwalk, CT, USA). Phytic acid using the Association of Official Analytical Chemists (AOAC) method and tanmic acids were also analysed from the test food ${ }^{(12-13)}$.

\section{Study 1: Determination of mineral availability, in vitro}

$\mathrm{Fe}, \mathrm{Zn}$ and $\mathrm{Ca}$ availability was determined following the method of Trinidad et al. ${ }^{(14)}$. This method simulated the amount of mineral released that can be potentially absorbed in the small intestine and colon.

\section{Study 2: Glycaemic index of legumes}

In the study eight legumes were used as test foods: cowpeas, mung beans, pole sitao, chickpeas, green peas, groundnuts, pigeon peas and kidney beans. The test foods were prepared at the Nutrient Availability Section, Food and Nutrition Research Institute, Department of Science and Technology. Legumes were soaked in water overnight, boiled the next day (time of cooking ranged from 20 to $45 \mathrm{~min}$ ), cooled overnight and fed to subjects after warming them in a microwave oven. The control (standard) food was white bread prepared in a bread maker (Regal Kitchen Pro Collection, KCTNO4584, made in China, serviced in USA) following the formulation of Wolever et al. ${ }^{(9)}$ as follows: $334 \mathrm{~g}$ flour (Wooden Spoon All Purpose Flour; Pillmico Mauri Food Corporation, Kwalan Cove, Iligan City, Philippines), $4 \mathrm{~g}$ salt, $5 \mathrm{~g}$ yeast, $7 \mathrm{~g}$ sucrose and $330 \mathrm{ml}$ water per $250 \mathrm{~g}$ carbohydrate loaf. Crust ends were not used for the test meals.

Study participants. Non-diabetic ( $n$ 7) and diabetic ( $n$ 6) human subjects (type 2, non-insulin-dependent diabetes mellitus) were physically examined by a medical doctor and evaluated by an endocrinologist on the basis of the following criteria: non-diabetics: BMI $20-30 \mathrm{~kg} / \mathrm{m}^{2}$ (WHO criteria), fasting blood glucose $4-7 \mathrm{mmol} / \mathrm{l}$, aged 35-60 years, no physical defect and non-smokers; diabetics: BMI $20-30 \mathrm{~kg} / \mathrm{m}^{2}$, fasting blood glucose $7.5-11.0 \mathrm{~mol} / 1$, aged 35-60 years, no intake of drugs, no complications and nonsmokers. Each subject was interviewed for physical activity and was asked to fill up a $3 \mathrm{~d}$ food intake recall form. Subjects with common food intake (pattern) and physical activity were included in the study. The participants' inclusion in the study was also based on fasting serum uric acid not greater than $405 \mu \mathrm{mol} / \mathrm{l}$. The diabetic participants were managed through dietary consultations and advice.

Protocol of the study. Using a randomised cross-over design, the control and test foods were fed in random order on separate occasions after an overnight fast. The control and test foods contained $50 \mathrm{~g}$ available carbohydrates. The participants were told to fast overnight $(10-12 \mathrm{~h})$ before the start of the study. Feeding of white bread and test foods were repeated twice.

Blood samples approximately of $0.3-0.4 \mathrm{ml}$ were collected by finger prick before and after feeding in a $4 \mathrm{~mm}$ diameter and $10 \mathrm{~cm}$ long capillary tubing (PYREX ${ }^{\circledR}$; Corning, Inc., Corning, NY, USA) and sealed (Jockel Seal Sticks Cement, catalogue no. 2454 W15; AH Thomas, Philadelphia, PA, USA). For non-diabetic participants, samples were collected at $0 \mathrm{~h}$ and every $15 \mathrm{~min}$ after feeding for $1 \mathrm{~h}$ and every $30 \mathrm{~min}$ for the next $1 \mathrm{~h}$ while for diabetics, samples were collected at $0 \mathrm{~h}$ and at $30 \mathrm{~min}$ interval after feeding for a period of $3 \mathrm{~h}$. The serum was separated from the blood using a refrigerated centrifuge after all the blood was collected (Expender Centrifuge; Eppendorf, Hamburg, Germany), and analysed for glucose levels on the same day using a clinical chemistry analyser (ARTAX Menarini Diagnostics, Firenze, Italy) after calibration with the glucose standard (Glucofix Reagent 1; Menarini Diagnostics, Firenze, Italy). The area under the glucose response curve for each food, ignoring area below the fasting level, was calculated geometrically ${ }^{(15)}$. The GI of each food was expressed as the percentage of the mean glucose response of the test food divided by the standard food taken by the same subject and was determined by the following formula:

$$
\begin{aligned}
\mathrm{GI}= & (\text { IAUC of the test food } \times 100) /(\text { IAUC of the } \\
& \text { standard food }),
\end{aligned}
$$

where IAUC is the incremental area under the glucose response curve.

\section{Study 3: Cholesterol-lowering effect in human subjects with moderately raised serum cholesterol levels}

In the study six legumes were used, as follows: mung beans, chickpeas, green peas, groundnuts, pigeon peas and kidney beans. The test foods were prepared as described above.

Study participants. The study participants were selected based on the following criteria: moderately raised serum cholesterol level (200-239 mg cholesterol per $100 \mathrm{~g}$ serum based on WHO criteria); aged 30-60 years, no drug intake for cholesterol-lowering and no complications. They were interviewed to obtain data on their usual $3 \mathrm{~d}$ food intake, physical activity and smoking habits. The total number of study participants in the study was twenty (eighteen females and two males).

Protocol of the study. The study was conducted in a 22-week period (5.5 months), consisting of six 2-week experimental periods, each experimental period separated by a 2-week washout period for a total of five washout periods. The test foods contained $50 \mathrm{~g}$ available carbohydrates. 
Study participants served as their own control. The study participants were made to fast overnight $(10-12 \mathrm{~h}$ fasting) before the study. They were weighed, their blood pressure measured and a sample of blood from their forearm vein was taken. The study participants were given the test foods to consume every day to ensure compliance of the participants, except on Fridays when three test foods were given to include Saturday and Sunday intakes. They recorded their respective food intakes for the duration of the experimental study. On day 15 , blood was drawn from the participants after an overnight fast. Blood samples were taken into plain glass tubes from the forearm vein, left to clot at room temperature, centrifuged, and the serum separated. Total cholesterol, HDL-cholesterol and TAG were measured in a clinical chemistry analyser (ARTAX; Menarini Diagnostic, Florence, Italy) against standards (cholesterol, cholesterol standard, $2000 \mathrm{mg} / \mathrm{l}$; HDLcholesterol, cholesterol standard, $500 \mathrm{mg} / \mathrm{l}$; TAG, glycerol standard, $2000 \mathrm{mg} / \mathrm{l}$; all Sentinel $\mathrm{CH}$, Milan, Italy). The amount of LDL was estimated from the formula used by Wolever et al. ${ }^{(16)}$ as follows:

$$
\mathrm{LDL}=((\text { total cholesterol }-\mathrm{HDL})-\mathrm{TAG} / 2 \cdot 2)
$$

The study was conducted according to the guidelines laid down in the Declaration of Helsinki and all procedures involving human subjects were approved by the National Human Ethics Committee, Philippine Council for Health Research and Development, Department of Science and Technology, Metro Manila, Philippines. Voluntary written consent forms were obtained from the study participants.

\section{Statistical analysis}

The sample size was chosen to achieve $80 \%$ power at the $5 \%$ level of significance. Differences between test foods and biomarkers were determined by two-way repeated-measures ANOVA and Duncan's multiple-range test, and correlation coefficients were determined to relate GI and the different nutrients present in the test foods using SAS (SAS Institute, Inc., Gary, NC, USA).

\section{Results}

Study 1: Determination of mineral availability, in vitro

Table 1 shows the total mineral, phytic acid and tannic acid content of legumes. Among the legumes, soyabeans, pole sitao, cowpeas and mung beans are the best sources of $\mathrm{Fe}$ while pole sitao, groundnuts and cowpeas are the best sources of Zn. Soyabeans, kidney beans, chickpeas and pigeon peas are the best sources of $\mathrm{Ca}$. A previous study showed that the best source of dietary fibre among legumes was soyabeans ( $46.9 \mathrm{~g}$ per $100 \mathrm{~g}$ sample) followed by pole sitao ( $35 \mathrm{~g}$ per $100 \mathrm{~g}$ sample) and cowpeas $(34 \mathrm{~g} \text { per } 100 \mathrm{~g} \text { sample })^{(10)}$. Soyabeans have the highest phytic acid content followed by cowpeas, mung beans and groundnuts. Tannic acid is highest in pigeon peas followed by pole sitao and cowpeas. Dialysable mineral as a percentage of total mineral content of legumes is used as a measure of mineral availability. Fe availability is significantly greater from lima beans (Table $2 ; P<0.05$ ), while for $\mathrm{Zn}$ availability, kidney beans and lima beans $(P<0.05)$. Ca availability is significantly greater from pigeon peas, green peas and pole sitao $(P<0.05)$.

\section{Study 2: Glycaemic index of legumes}

The BMI of the non-diabetic subjects was found to be $25 \cdot 0$ (SD 0.6) $\mathrm{kg} / \mathrm{m}^{2}$; for the diabetics, BMI was 26.8 (SD 1.2) $\mathrm{kg} / \mathrm{m}^{2}$. There were no significant differences between the non-diabetic and diabetic subjects for age and BMI. There were significant differences observed between subjects for the fasting blood glucose; that of diabetic subjects $(7.5-8.5 \mathrm{mmol} / \mathrm{l}$ glucose) was significantly greater than that of the normal subjects $(4-6 \mathrm{mmol} / \mathrm{l}$ glucose; $P<0.05)$. The initial blood glucose obtained from the non-diabetic participants for all test foods did not exceed $6.0 \mathrm{mmol} / \mathrm{l}$. All participants were able to consume all test foods (white bread twice, test foods twice). Table 3 shows the GI of the test foods. The GI of the test foods were adjusted to 0.7 to obtain GI value for the same food on the glucose scale. Local legumes are considered low-GI foods $(\mathrm{GI}<55)$ (Table 3). Significant differences in GI were observed in non-diabetic and diabetic participants for the following

Table 1. Mineral, phytic acid and tannic acid content of legumes (mg per $100 \mathrm{~g} \mathrm{sample)*}$

(Mean values with their standard errors)

\begin{tabular}{|c|c|c|c|c|c|c|c|c|c|c|}
\hline & \multicolumn{2}{|c|}{$\mathrm{Fe}$} & \multicolumn{2}{|c|}{$\mathrm{Zn}$} & \multicolumn{2}{|c|}{$\mathrm{Ca}$} & \multicolumn{2}{|c|}{ Phytic acid } & \multicolumn{2}{|c|}{ Tannic acid } \\
\hline & Mean & SEM & Mean & SEM & Mean & SEM & Mean & SEM & Mean & SEM \\
\hline Cowpeas (Vigna unguiculata (L.) Walp.) & $10 \cdot 6^{c, y}$ & $0 \cdot 1$ & $6 \cdot 5^{a, b, z}$ & 0.6 & $20 \cdot 9^{e, x}$ & 0.2 & $542 \cdot 4^{\mathrm{b}}$ & $10 \cdot 4$ & $368 \cdot 8^{\mathrm{c}}$ & $6 \cdot 6$ \\
\hline Mung beans ( $V$. radiata (L.) R. Wilczek) & $10 \cdot 7^{c, y}$ & 0.2 & $4 \cdot 8^{\mathrm{c}, \mathrm{d}, \mathrm{z}}$ & 0.4 & $27 \cdot 3^{\mathrm{d}, \mathrm{x}}$ & 0.9 & $488 \cdot 6^{\mathrm{c}}$ & 0.8 & $269 \cdot 8^{f}$ & 1.6 \\
\hline Pole sitao (V. unguiculata subsp. sesquipedalis (L.) Verde) & $11 \cdot 3^{b, y}$ & 0.2 & $7 \cdot 4^{\mathrm{a}, \mathrm{z}}$ & 0.3 & $20 \cdot 0^{f, x}$ & 0.1 & $433.7^{d}$ & $4 \cdot 7$ & $522 \cdot 6^{\mathrm{b}}$ & 4.3 \\
\hline Chickpeas (Cicer arietinum) & $7 \cdot 7^{\mathrm{f}, \mathrm{y}}$ & 0.2 & $4 \cdot 7^{\mathrm{d}, \mathrm{z}}$ & 0.1 & $51 \cdot 7^{\mathrm{b}, \mathrm{x}}$ & 0.4 & $278 \cdot 7^{\mathrm{g}}$ & 0.2 & $72 \cdot 1^{\mathrm{i}}$ & 0.8 \\
\hline Green peas (Pisum sativum L.) & $7 \cdot 3^{f, y}$ & 0.3 & $5 \cdot 4^{\mathrm{c}, \mathrm{z}}$ & 0.5 & $33 \cdot 1^{\mathrm{c}, \mathrm{x}}$ & 3.8 & $308 \cdot 5^{f}$ & $3 \cdot 3$ & $82 \cdot 1^{\mathrm{h}}$ & $2 \cdot 2$ \\
\hline Groundnuts (Arachis hypogaea L.) & $4 \cdot 2^{\mathrm{h}, \mathrm{z}}$ & 0.3 & $7 \cdot 3^{a, b, y}$ & $1 \cdot 2$ & $10 \cdot 6^{g, x}$ & 0.3 & $470.9^{c}$ & $9 \cdot 4$ & $312 \cdot 6^{\mathrm{d}}$ & 2.9 \\
\hline Pigeon peas (Cajanus cajan) & $5 \cdot 4^{\mathrm{g}, \mathrm{z}}$ & 0.1 & $6 \cdot 1^{b, y}$ & 0.1 & $51 \cdot 4^{\mathrm{b}, \mathrm{x}}$ & 4.7 & $347 \cdot 2^{\mathrm{e}}$ & $2 \cdot 0$ & $604 \cdot 6^{\mathrm{a}}$ & $1 \cdot 1$ \\
\hline Kidney beans (Phaseolus vulgaris L.) & $9 \cdot 8^{\mathrm{d}, \mathrm{y}}$ & 0.5 & $4 \cdot 2^{\mathrm{d}, \mathrm{z}}$ & 0.3 & $56 \cdot 2^{\mathrm{b}, \mathrm{x}}$ & $2 \cdot 3$ & $342 \cdot 4^{\mathrm{e}}$ & 5.6 & $92 \cdot 1^{\mathrm{h}}$ & 1.0 \\
\hline Lima beans (Phaseolus lunatus) & $8 \cdot 6^{e, y}$ & 0.5 & $5 \cdot 1^{b, c, z}$ & 1.3 & $31 \cdot 7^{\mathrm{c}, \mathrm{x}}$ & $2 \cdot 2$ & $341.2^{\mathrm{e}}$ & 4.4 & $303.9^{\mathrm{e}}$ & $3 \cdot 1$ \\
\hline Soyabeans (Glycine soja) & $16 \cdot 1^{\mathrm{a}, \mathrm{y}}$ & 0.2 & $6 \cdot 6^{\mathrm{b}, \mathrm{z}}$ & 0.3 & $150 \cdot 2^{a, x}$ & $1 \cdot 2$ & 755.5 & $3 \cdot 7^{\mathrm{a}}$ & $219.9^{\mathrm{g}}$ & 1.2 \\
\hline
\end{tabular}

${ }^{\mathrm{a}-\mathrm{h}}$ Mean values within a column with unlike superscript letters were significantly different $(P<0.05)$.

$\mathrm{x}, \mathrm{y}, \mathrm{z}$ Mean values for minerals within a row with unlike superscript letters were significantly different $(P<0.05)$.

* The mineral, phytic acid and tannic acid contents of legumes were analysed as part of the mineral availability, in vitro study. 
Table 2. Mineral availability in vitro from legumes*

(Mean values with their standard errors)

\begin{tabular}{|c|c|c|c|c|c|c|}
\hline & \multicolumn{6}{|c|}{ Percentage of total mineral content $(\mathrm{mg} / \mathrm{mg})$} \\
\hline & \multicolumn{2}{|c|}{$\mathrm{Fe}$} & \multicolumn{2}{|c|}{$\mathrm{Zn}$} & \multicolumn{2}{|c|}{$\mathrm{Ca}$} \\
\hline & Mean & SEM & Mean & SEM & Mean & SEM \\
\hline Cowpeas (Vigna unguiculata (L.) Walp.) & $1 \cdot 9^{\mathrm{d}, \mathrm{z}}$ & 0.3 & $46 \cdot 9^{a, b, y}$ & $4 \cdot 3$ & $64 \cdot 2^{b, x}$ & $3 \cdot 2$ \\
\hline Mung beans ( $V$. radiata (L.) R. Wilczek) & $7 \cdot 3^{\mathrm{b}, \mathrm{z}}$ & 0.6 & $40 \cdot 4^{\mathrm{b}, \mathrm{c}, \mathrm{y}}$ & 3.4 & $60 \cdot 0^{b, x}$ & $3 \cdot 7$ \\
\hline Pole sitao (V. unguiculata subsp. sesquipedalis (L.) Verde) & $2 \cdot 6^{c, d, z}$ & 0.9 & $38 \cdot 8^{\mathrm{c}, \mathrm{y}}$ & 0.8 & $65 \cdot 2^{a, x}$ & $5 \cdot 5$ \\
\hline Chickpeas (Cicer arietinum) & $3 \cdot 8^{c, z}$ & 0.8 & $16 \cdot 7^{f, y}$ & 0.7 & $41.9^{\mathrm{c}, \mathrm{x}}$ & 0.1 \\
\hline Green peas (Pisum sativum L.) & $4 \cdot 1^{\mathrm{c}, \mathrm{z}}$ & $2 \cdot 3$ & $30 \cdot 6^{\mathrm{d}, \mathrm{y}}$ & $2 \cdot 3$ & $68 \cdot 5^{a, x}$ & $2 \cdot 1$ \\
\hline Groundnuts (Arachis hypogaea L.) & $1 \cdot 3^{\mathrm{d}, \mathrm{z}}$ & $1 \cdot 1$ & $7 \cdot 9^{g, y}$ & 1.3 & $14 \cdot 6^{e, x}$ & $2 \cdot 8$ \\
\hline Pigeon peas (Cajanus cajan) & $2 \cdot 7^{\mathrm{c}, \mathrm{d}, \mathrm{z}}$ & $2 \cdot 0$ & $31 \cdot 9^{\mathrm{d}, \mathrm{y}}$ & $4 \cdot 7$ & $75 \cdot 1^{a, x}$ & $7 \cdot 1$ \\
\hline Kidney beans (Phaseolus vulgaris L.) & $5 \cdot 7^{b, c, z}$ & $2 \cdot 0$ & $49 \cdot 3^{a, x}$ & 4.5 & $30 \cdot 0^{\mathrm{d}, \mathrm{y}}$ & 0.8 \\
\hline Lima beans (Phaseolus lunatus) & $9 \cdot 5^{a, z}$ & 0.1 & $47 \cdot 4^{\mathrm{a}, \mathrm{y}}$ & 0.7 & $56 \cdot 6^{\mathrm{b}, \mathrm{x}}$ & 4.4 \\
\hline Soyabeans (Glycine soja) & $8 \cdot 2^{\mathrm{b}, \mathrm{z}}$ & 0.6 & $21 \cdot 8^{e, x}$ & 1.8 & $16 \cdot 7^{e, y}$ & 0.4 \\
\hline
\end{tabular}

${ }^{a-g}$ Mean values within a column with unlike superscript letters were significantly different $(P<0.05)$.

$x, y, z$ Mean values within a row with unlike superscript letters were significantly different $(P<0.05)$.

${ }^{*}$ Mineral availability in vitro estimates the mineral released from food for potential absorption in the small intestine and colon.

legumes: cowpeas, mung beans, pole sitao and kidney beans (Table 3; $P<0 \cdot 05$ ).

\section{Study 3: Cholesterol-lowering effect in human subjects with moderately raised serum cholesterol levels}

There was a decreasing trend in both total and LDL-cholesterol levels among study participants fed with legumes for $14 \mathrm{~d}$ (Table 4). However, only kidney beans gave significant decreases for both total (6\%) and LDL-cholesterol (9\%) and groundnuts for total cholesterol $(7 \%)$. No significant increase in HDL-cholesterol was observed. Similar results were observed for TAG (Table 4).

\section{Discussion}

Mineral availability from legumes differed and may be attributed to the mineral content, mineral-mineral interaction, and the presence of phytic and tannic acids ${ }^{(17-21)}$. Fe availability from legumes was reduced by higher tannic acid content. The phytic and tannic acid content of legumes did not affect
$\mathrm{Zn}$ availability except for groundnuts in terms of phytic acid content. In general, it was observed that when $\mathrm{Ca}$ and $\mathrm{Zn}$ availability was high, Fe availability was low from all of the legumes studied (Table 2).

Results of the study showed that equal carbohydrates portions $(50 \mathrm{~g}$ available carbohydrates) of the different test foods do not have the same glycaemic effect in non-diabetic and diabetic participants (Table 3). The amount of dietary fibre present in the test foods may have caused significant differences in the GI of legumes. Dietary fibre may cause a delay in the glycaemic responses of legumes similar to previous studies on dietary fibre and GI of foods ${ }^{(4,5,15)}$. The increasing levels of dietary fibre, viscosity, cooking, particle size, form of food and starch structure may all be attributed to slower nutrient absorption and delayed transit time ${ }^{(22-24)}$. Considering the dietary fibre present in whole foods, insoluble fibre was related more strongly to the GI than soluble fibre content $^{(23)}$. The insoluble fibre content of legumes was significantly greater than that of soluble fibre in the present study ${ }^{(10)}$. On the other hand, most of the legumes studied contain protein in the range of $20-28 \mathrm{~g}$ per $100 \mathrm{~g}^{(10)}$. According to several

Table 3. Glycaemic index (GI) of local legumes in non-diabetic and diabetic participants*

(Mean values with their standard errors)

\begin{tabular}{|c|c|c|c|c|}
\hline & \multicolumn{2}{|c|}{ Non-diabetic $(n 7)$} & \multicolumn{2}{|c|}{ Diabetic $(n 6)$} \\
\hline & Mean & SEM & Mean & SEM \\
\hline Cowpeas (Vigna unguiculata (L.) Walp.) & $11^{\mathrm{b}, \mathrm{x}}$ & 1 & $7^{\mathrm{b}, \mathrm{y}}$ & 1 \\
\hline Mung beans ( $V$. radiata (L.) R. Wilczek) & $15^{\mathrm{a}, \mathrm{x}}$ & 1 & $11^{\mathrm{a}, \mathrm{y}}$ & 2 \\
\hline Pole sitao (V. unguiculata subsp. sesquipedalis (L.) Verde) & $9^{c, x}$ & 1 & $6^{b, c, y}$ & 1 \\
\hline Chickpeas (Cicer arietinum) & $6^{\mathrm{e}, \mathrm{x}}$ & 1 & $5^{\mathrm{c}, \mathrm{x}}$ & 1 \\
\hline Green peas (Pisum sativum L.) & $9^{b, c, x}$ & 2 & $9^{a, x}$ & 2 \\
\hline Groundnuts (Arachis hypogaea L.) & $7^{\mathrm{d}, \mathrm{x}}$ & 1 & $5^{\mathrm{c}, \mathrm{x}}$ & 1 \\
\hline Pigeon peas (Cajanus cajan) & $9^{\mathrm{c}, \mathrm{x}}$ & 1 & $7^{\mathrm{a}, \mathrm{b}, \mathrm{c}, \mathrm{x}}$ & 1 \\
\hline Kidney beans (Phaseolus vulgaris L.) & $13^{a, x}$ & 1 & $9^{a, b, y}$ & 1 \\
\hline
\end{tabular}

${ }^{a-e}$ Mean values within a column with unlike superscript letters were significantly different $(P<0.05)$.

${ }^{x, y}$ Mean values within a row with unlike superscript letters were significantly different $(P<0.05)$.

* The Gl of the different legumes were calculated from the glucose response of the food ingested in diabetic and non-diabetic participants by dividing the incremental area under the curve (IAUC) of the legume by the IAUC of standard glucose multiplied by 100 . 
investigators, $20-30 \mathrm{~g}$ dietary protein increased insulin responses sufficiently and reduced glycaemic responses especially in individuals with non-insulin-dependent diabetes mellitus ${ }^{(25,26)}$. The protein content of the test foods may have played a significant role in the low GI of some legumes tested. The fat content of legumes ranged from 0.2 to $5.8 \mathrm{~g}$ per $100 \mathrm{~g}$ and may not affect the glycaemic responses of the study participants from the foods ingested ${ }^{(10)}$. A sufficient amount of fat in food $(23 \mathrm{~g} \mathrm{fat} / \mathrm{kg})$ can cause an early $(0-90 \mathrm{~min})$ decrease in glucose response but does not affect the overall glucose response to food ${ }^{(25)}$. The differences in glucose responses between the two groups (non-diabetics and diabetics) may be due to rates of digestion and absorption in relation to the food ingested.

Legumes have been shown to be hypercholesterolaemic foods, for example, kidney beans and groundnuts. Studies on mixed legumes suggested that their consumption lowers LDL-cholesterol by partially interrupting the enterohepatic circulation of bile acids and increases cholesterol saturation of bile by increasing the secretion of cholesterol ${ }^{(27)}$. Consumption of pinto beans showed decreases in both LDL- and HDLcholesterol without affecting serum TAG, VLDL-cholesterol, or glucose ${ }^{(28)}$. Epidemiological studies revealed significant inverse relationships between legume intake and the risk of CVD and CHD. The hypocholesterolaemic property of dietary fibre in legumes is associated with the water-soluble fraction of fibre which is fermentable in the colon, for example, galactomannans, uronic acid, glucomannans and galacturonic acids. However, various water-soluble fibres may differ in their ability to reduce serum cholesterol ${ }^{(29,30)}$. The Lipid Research Clinics Coronary Primary Prevention Trial predicted that for every $1 \%$ decrease in serum cholesterol concentration, there is a decreased risk of CHD of $2 \%{ }^{(31)}$. There was no significant increase or decrease in HDL-cholesterol levels of all study participants. The concentration of serum HDL-cholesterol is affected by alcohol intake and $\mathrm{BMI}^{(32)}$. However, all study participants were not alcohol drinkers and BMI was not significantly different between participants during the duration of the experimental period. The study on cholesterol-lowering effects was a short-term (acute) study. A longer-term nutrition intervention study may give a more conclusive result.

\section{Conclusion}

In conclusion: (a) mineral availability from legumes studied differed and may be attributed to the mineral content, mineralmineral interaction, and the presence of phytic and tannic acids; (b) legumes are considered to be low-GI foods $(\mathrm{GI}<55)$; (c) some legumes have shown hypocholesterolaemic effects. The study may have a significant role in the proper control and management of chronic diseases, for example, obesity, diabetes mellitus, cancer and CVD, and may also contribute in decreasing the prevalence of $\mathrm{Fe}, \mathrm{Zn}$ and $\mathrm{Ca}$ deficiency. The study can be a scientific basis for considering legumes as functional foods or functional food ingredients to supplement rice, bread and other food products. The utilisation of legumes as functional foods will also encourage the industry and farmers to produce value-added or healthy products from legumes as well as increase their production. 


\section{Acknowledgements}

The project was supported by the Food and Nutrition Research Institute, Department of Science and Technology (FNRI, DOST), Philippines.

The authors wish to thank Mr Zoilo B. Villanueva, Ms Elaine S. Perez, Ms Josefina A. Desnacido and Ms Paz S. Lara, Nutritional Biochemistry Section, FNRI, DOST for their technical assistance.

T. P. T. was the project leader of the study and supervised the implementation of the project, analysed the data and results, and wrote the paper for publication. A. C. M. and A. S. L. determined the mineral availability from food samples. R. S. S. was in charge of feeding the participants with test samples and analysis of lipid profiles, while R. R. E. prepared the food samples and analysed the glucose responses of study participants. All authors read and approved the findings of the study.

There is no conflict of interest in the publication of this paper.

\section{References}

1. Roberfroid M (1997) Health benefits of non-digestible oligosaccharides. In Dietary Fiber in Health and Disease (Advances in Experimental Biology), p. 427 [D Kritchevsky and C Bonfield, editors]. New York: Plenum Press.

2. Chen WJL, Anderson JW \& Jenkins DJA (1984) Propionate may mediate the hypocholesterolemic effects of certain soluble plant fibers in cholesterol-fed rats. Proc Soc Exp Biol Med 175, 215-218.

3. Eastwood MA, Brydon WG \& Tadesse K (1980) Effect of fiber on colonic function. In Medical Aspects of Dietary Fiber, pp. 1-26 [GA Spiller and RM Kay, editors]. New York: Plenum Press.

4. Creutzfeldt W (1983) Introduction. In Delaying Absorption as a Therapeutic Principle in Metabolic Diseases, p. 1 [W Creutzfeldt and RU Folsch, editors]. New York, NY: Thiem-Stratton.

5. Jenkins DJA, Ghafari A, Wolever TMS, et al. (1982) Relationship between rate of digestion of foods and post-prandial glycemia. Diabetologia 22, 250-255.

6. Collier GR, Giudici S, Kalmusky J, et al. (1988) Low glycemic index starchy foods improve glucose control and lower serum cholesterol in diabetic children. Diabetes Nutr Metab 1, 11-19.

7. Fontvieille AM, Acosta M, Rizkalla SW, et al. (1988) A moderate switch from high to low glycemic index foods for three weeks improves the metabolic control of type I (IDDM) diabetic subjects. Diabetes Nutr Metab 1, 139-143.

8. Brand JC, Calaguiri S, Crossman S, et al. (1991) Low glycemic index foods improve long-term glycemic control in NIDDM. Diabetes Care 14, 95-101.

9. Wolever TMS, Jenkins DJA, Vuksan V, et al. (1992) Beneficial effect of a low glycemic index diet in type 2 diabetes. Diabetes Med 9, 451-458.

10. Mallillin AC, Trinidad TP, Raterta R, et al. (2008) Dietary fiber and fermentability characteristics of root crops and legumes. $\mathrm{Br}$ J Nutr 100, 485-488.

11. Association of Official Analytical Chemists (1995) Official Methods of Analysis, 991.43 Supplement. Arlington, VA: AOAC.

12. Association of Official Analytical Chemists (1986) Phytate in foods: anion exchange method. J Assoc Off Anal Chem 69, 2.

13. Earp CF, Ring SH \& Rooney LW (1981) Evaluation of several methods to determine tannins in sorghum with varying kernel characteristics. Cereal Chem 58, 134-138.
14. Trinidad TP, Wolever TMS \& Thompson LU (1996) Availability of calcium for absorption in the small intestine and colon from diets containing available and unavailable carbohydrates: an in vitro assessment. Int J Food Sci Nutr 47, 83-88.

15. Wolever TMS, Katzman-Relle L, Jenkins JL, et al. (1994) Glycemic index of 102 complex carbohydrate foods in patients with diabetes. Nutr Res 14, 651-669.

16. Wolever TMS, Jenkins DJA, Mueller S, et al. (1994) Method of administration influences the serum-cholesterol lowering effect of psyllium. Am J Clin Nutr 59, 1055-1059.

17. Cook JD, Dassenko SA \& Whittaker P (1991) Calcium supplementation: effect on iron absorption. Am J Clin Nutr 53, 106-111.

18. Davidsson L, Almgren A, Sandstrom B, et al. (1995) Zinc absorption in adult humans: the effect of iron fortification. $\mathrm{Br}$ J Nutr 74, 417-425.

19. Davidsson L, Kastenmayer P \& Hurrell RF (1994) Sodium iron EDTA as a food fortificant: the effect on the absorption and retention of zinc and calcium in women. Am J Clin Nutr $\mathbf{6 0}$, 231-237.

20. Forbes RM, Erdman JW Jr, Parker HM, et al. (1983) Bioavailability of zinc in coagulated soy protein (tofu) to rats and effect of dietary calcium at a constant phytate:zinc ratio. J Nutr 113, 205-210.

21. Brune M, Rossander L \& Hallberg L (1989) Iron absorption and phenolic compounds: importance of different phenolic structures. Eur J Clin Nutr 43, 547-548.

22. Trinidad TP, Valdez DH, Loyola AS, et al. (2003) Glycemic index of coconut flour products in normal and diabetic subjects. Br J Nutr 90, 551-556.

23. Jenkins DJA, Wolever TMS, Leeds AR, et al. (1978) Dietary fibers, fiber analogues and glucose tolerance: importance of viscosity. BMJ 2, 1744-1746.

24. Simpson RW, McDonald J, Wahlqvist ML, et al. (1985) Macronutrients have different metabolic effects in non-diabetics and diabetics. Am J Clin Nutr 42, 449-453.

25. Peters AL \& Davidson MB (1993) Protein and fat effects on glucose response and insulin requirements in subjects with insulin-dependent diabetes mellitus. Am $J$ Clin Nutr 58, $555-560$.

26. Nuttall FD, Mooradian AD, Gannon MC, et al. (1984) Effect of protein ingestion on the glucose and insulin response to a standardized oral glucose load. Diabetes Care 7, 465-470.

27. Duane WC (1997) Effects of legume consumption on serum cholesterol, biliary lipids, and sterol metabolism in humans. $J$ Lipid Res 38, 1120-1128.

28. Finley JW, Burrell JB \& Reeves PG (2007) Pinto bean consumption changes SCFA profiles in fecal fermentation, bacterial populations of the lower bowel, and lipid profiles in blood of humans. J Nutr 135, 2391-2398.

29. Jenkins DJA, Leeds AR, Newton C, et al. (1975) Effect of pectin, guar gum and wheat fibre on serum-cholesterol. Lancet i, 1116-1117.

30. Bell LP, Hectorn KJ, Reynolds H, et al. (1990) Cholesterol-lowering effects of soluble fiber cereals as part of a prudent diet for patients with mild to moderate hypercholesterolemia. Am J Clin Nutr 52, 1020-1026.

31. Anonymous (1984) The Lipid Research Clinics Coronary Primary Prevention Trial results: II. The relationship of reduction in incidence of coronary heart disease to cholesterol lowering. JAMA 251, 365-374.

32. Bolton-Smith C, Woodward M, Smith WCS, et al. (1991) Dietary and non-dietary predictors of serum total and HDLcholesterol in men and women: results from the Scottish Heart Health Study. Int J Epidemiol 20, 95-104. 